Published by Al-Nahrain College of Medicine P-ISSN 1681-6579

E-ISSN 2224-4719

Email: iraqijms@colmed-alnahrain.edu.iq

http://www.colmed-alnahrain.edu.iq

http://www.iraqijms.net

Iraqi JMS 2018; Vol. 16(2)

\title{
Intramedullary Nailing Versus Fixed Angled Blade Plating for Treatment of Subtrochanteric Femoral Fracture
}

\author{
Ahmed I. Joda ${ }^{1}$ FIBMS (ORTHO), Alaa A. Aldookhi ${ }^{2}$ MBChB, Ahmed S. Abd Ali ${ }^{3}$ FIBMS (ORTHO) \\ ${ }^{1}$ Section of Orthopedic, Dept. of Surgery, Al Al-Imamein Al-kadhimein Medical City, Baghdad, Iraq, ${ }^{2}$ Section of \\ Orthopedic, Dept. of Surgery, Baghdad Medical City, Baghdad, Iraq, ${ }^{3}$ Section of Orthopedic, Dept. of Surgery, College \\ of Medicine, Al-Nahrain University, Baghdad, Iraq,
}

\begin{abstract}
Background The subtrochanteric fractures represent $7-44 \%$ of the fractures of proximal femur caused by low energy trauma in elderly patients or high energy trauma in younger age group. Different surgical options used to treat and fix this fractures that could be Intramedullary devices like intramedullary nail or extramedullary devices like fixed angle blade plate.

Objective Comparing the result of close reduction and internal fixation with intramedullary nail to the open reduction and internal fixation with 95 -angled blade plate for treatment of subtrochanteric fractures.

Methods Prospective multicenter study was done in Al-Imamein Al-kadhimein Medical City and Al-Wasity Teaching Hospital for thirty patients with close and open (Gustilo type-1) subtrochanteric femoral fractures between December-2014 and September-2016. Eighteen patients (8 closed +10 open fractures) treated with Intramedullary nail (IMN) were compared to twelve patients ( 9 closed +3 open fractures) treated with open reduction and 95 -angled blade plate fixation (BP).

Results There were significant statistical differences between the two groups. The IMN group show better outcome regarding the mean union rate time (IMN were 16 weeks while in the BP were 22 weeks). Mean hospitalization stay (IMN were 82 hours while in BP were 110 hours) and rate of infection (IMN 0\% while in BP were 16\%), but no statistical difference regarding the mean operation time (IMN were 1.59 hour while in BP were 1.43 hour) and functional outcome (HHS in IMN were 82 while in BP were 79).

Conclusion Closed reduction and internal fixation with Intramedullary Nail is preferable (for Close and Open Gustilo's type-1 Subtrochanteric fractures) when compared to the open reduction and Internal Fixation with 95-angled Blade Plate.

Keywords Subtrochanteric femur fractures, closed reduction intramedullary nail fixation, open reduction internal fixation, fixed angle blade plate.

Citation Joda AI, Aldookhi AA, Abd Ali AS. Intramedullary nailing versus fixed angled blade plating for treatment of subtrochanteric femoral fracture. Iraqi JMS. 2018; 16(2): 125-132. doi: 10.22578/IJMS.16.2.3
\end{abstract}

List of abbreviations: ATLS = Advance Trauma Life Support, AAOS = American Academy of Orthopedic Surgery, BP = Blade plate, $\mathrm{IMN}=$ Intramedullary nail, $\mathrm{MVA}=$ Motor vehicle accident, OTA = Orthopedic Trauma Association, ORIF = Open reduction and internal fixation, PFN = Proximal femoral nail

\section{Introduction}

ubtrochanteric fractures involve the S segment of the proximal femur from the lesser trochanter to the isthmus. The major fracture involves a zone between the inferior border of the lesser trochanter and the junction of the proximal and middle one third of the femur (approximately a 5-cm segment) (Figure 1) ${ }^{(1)}$. Fractures in this area may extend proximally into the trochanteric area or neck and distally into the shaft.

Subtrochanteric femoral fractures are common and account for 7 to $44 \%$ of all proximal femoral fractures, depending on the classification used ${ }^{(2)}$. 
Compression, tensile, and torsional stresses of the subtrochanteric region have challenged orthopaedic surgeons with problems of malunion and non-union (3). Moreover, subtrochanteric fracture causes more blood loss than neck femur or intertrochanteric femur fracture ${ }^{(4)}$.

Extramedullary as well as intramedullary fixation techniques have been used to fix such fractures. Extramedullary fixation devices are used for more than a century but they have been associated with extensive surgical dissection, periosteum and soft tissue damage (5).

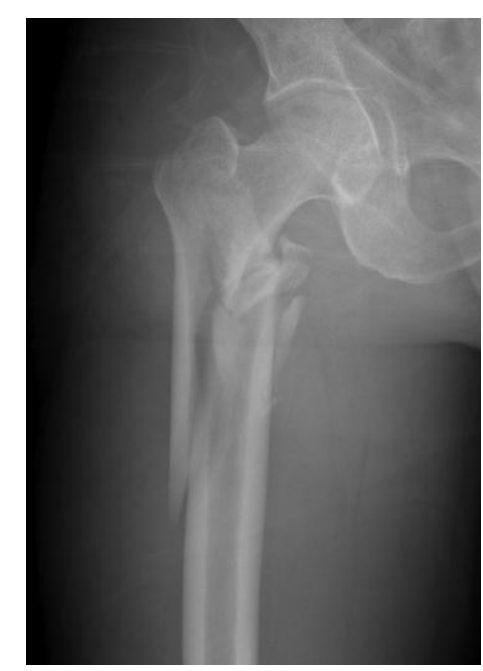

A

Superiority of intramedullary devices had been shown by biomechanical studies in comminuted subtrochanteric femur fractures (6). However, intramedullary fixation in subtrochanteric fractures is not without complication. Various authors have reported improper reduction with resultant mal-union or non-union after intramedullary nailing of comminuted fractures ${ }^{(7)}$.

The superiority or equality between the two fixation methods cannot be established due to dearth of literature on comparison of the two fixation methods.

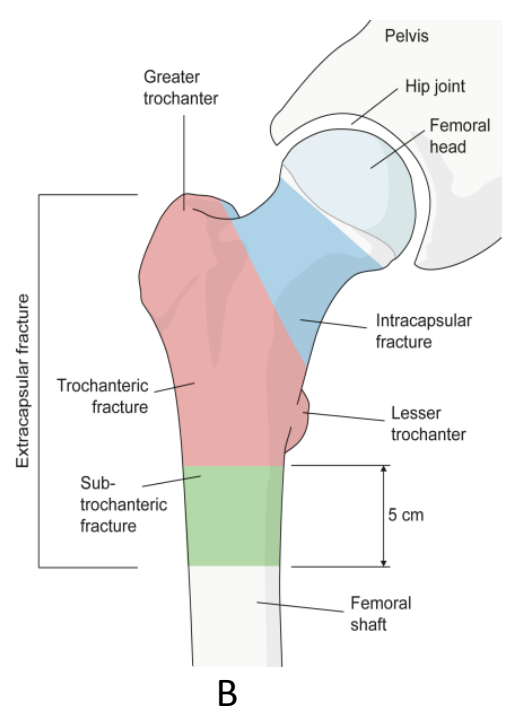

Figure 1. A) Typical subtrochanteric fracture extending to lesser trochanter in high energy trauma, B) Subtrochanyeric region (8)

\section{Epidemiology of subtrochanteric fracture}

Subtrochanteric femur fractures account for approximately $25 \%$ of all hip fractures and have a bimodal age and gender distribution. They are seen in either young men as a result of high-energy injuries (often highly comminuted and significantly displaced) or in elderly osteoporotic women as a result of low-energy falls (typically long spiral fractures) (Figure-4) (9).

The high-energy cases often have concomitant injuries involving thoracoabdominal and head injuries in $10 \%$ to $30 \%$ of patients and associated noncontiguous long bone, spine, and pelvic injuries in up to $50 \%$ of patients. Mortality rates as high as $21 \%$ have also been described ${ }^{(9,10)}$.

These fractures may also occur because of a stress riser in the lateral cortex of the proximal femur secondary to placing cannulated screws too distally during treatment of femoral neck fractures or drilling too inferiorly when performing core decompression or bone grafting for avascular necrosis of the hip (11).

Other causes include gunshot wounds and the more recently described "atypical" proximal femur fracture as a result of prolonged bisphosphonate therapy ${ }^{(12)}$. 


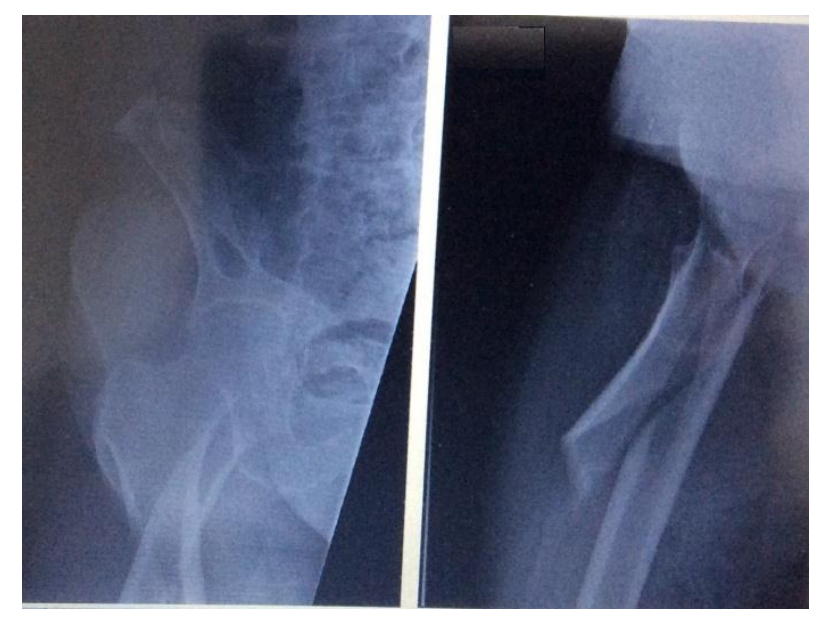

Figure 2. Typical long spiral fracture in elderly patient (9)

This study aimed to compare the result of closed reduction and internal fixation with intramedullary nailing to open reduction and internal fixation with 95 Blade plate for subtrochanteric (close and open type-1 Gustilo) fracture regarding union rate, hospitalization stay, operative time, infection rate, alignment and functional outcome.

\section{Methods}

Prospective comparative multicenter study was done at Al-Imamein Alkadhimein Medical city and Al-Wasity Teaching Hospital through the period from Dec. 2014 to September 2016 (total duration 1 year and 9 months) for thirty patients admitted to the hospitals with clinical and radiographic evidence of subtrochanteric femur fracture (fracture within $5 \mathrm{~cm}$ from distal border of lesser trochanter of femoral bone).

Eighteen patients ( 8 closed +10 open fractures) has been treated with Intramedullay Nail were matched to twelve patients ( 9 closed +3 open fractures) were treated with Open reduction and internal fixation with 95 angled Blade plate.

\section{Inclusion criteria}

- Closed subtrochanteric fracture.

- Open type of subtrochanteric fracture (Gustillo type 1) treated within 72 hours.

- Skeletally mature (closed proximal femoral and trochanteric physes).

\section{Exclusion criteria}

- Multiple injured patients.

- Ipsilateral femoral shaft and neck fracture.

- Previous operation or fracture on the same bone.

- Old burn or scar tissue near the fracture site.

- Vascular injury (acute or chronic).

- Sever peripheral vascular disease, cardiopulmonary instability, and uremia and cerebrovascular accident patients.

- Pathological fracture.

The patients were allocated into two group, Group 1; were treated with closed reduction and internal fixation with Intramedullary Nail (IMN), Group 2; were treated with Open reduction and internal fixation with 95 angled Blade plate (BP).

Patient's demographic detail, type of fracture, mechanism of injury, associated injuries, local and systemic complications were recorded.

Informed consent and permission for study protocol were taken from the patients.

\section{Results}

The Study population consists of 18 patients (8 closed fractures, 10 open fractures) in group 1 (treated with IMN) and 12 patients (9 closed fractures, 3 open fractures) in group 2 (treated with $\mathrm{BP})$. 
The mean age of the patients in group 1 was 50 years, while the mean age of the patients in group 2 was 55 years.

In both groups the mean age for males were 52 (range between 50-54 year) and the mean age of female were 55 (range between 50-60 years).

Regarding the affected side there are no significant deference in both groups, $p>0.05$.

Regarding the mechanism of injury: the major cause in both group was high energy trauma like road traffic accident $50 \%$ and fall from height $30 \%$ followed by low energy trauma $20 \%$.

When we compare the closed fracture treated with IMN to closed fracture treated with Open reduction and internal fixation (ORIF) with BP, statistical significant difference in union time and mean hospitalization Stay as the $p$-value $<0.05$, while no significant statistical difference regarding mean operative time and infection rate (Table 1).

Table 1. Results of treatment for close subtrochanteric fractures

\begin{tabular}{cccc}
\hline Results of treatment & $\begin{array}{c}\text { Group 1/IMN } \\
\text { Number=8 }\end{array}$ & $\begin{array}{c}\text { Group 2/ORIF with BP } \\
\text { Number=9 }\end{array}$ & P value \\
\hline Mean union time (weeks) & 16.38 & 22 & $\mathrm{~S}$ \\
Number of non-union & 0 & 1 & $\mathrm{NS}$ \\
Mean operative time (hours) & 1.52 & 1.86 & $\mathrm{NS}$ \\
Mean Hospitalization stay (hours) & 70 & 96 & $\mathrm{~S}$ \\
Infection rate & 0 & 1 & $\mathrm{NS}$ \\
Alignment & 0 & 1 & $\mathrm{NS}$ \\
\hline
\end{tabular}

$S=$ Significant $p$ value $\leq 0.05$, NS=Not significance $p$ value $>0.05$

While when we compare the result of treatment of open fractures treated with IMN (group 1) to open fractures treated with ORIF with BP fixation (Group 2), the significant statistical difference was in the infection rate, mean time for fracture union and mean hospitalization stay as $p$ value $<0.05$, while no significant difference regarding the mean operative time (Table 2).

Table 2. Results of treatments for open subtrochanteric fractures

\begin{tabular}{cccc}
\hline Results of treatment & $\begin{array}{c}\text { Group 1/IMN } \\
\text { Number=10 }\end{array}$ & $\begin{array}{c}\text { Group 2/BP } \\
\text { Number=3 }\end{array}$ & P value \\
\hline Mean union time (weeks) & 16 & 22.67 & $\mathrm{~S}$ \\
Number of non-union & 0 & 1 & $\mathrm{~S}$ \\
Mean operative time (hours) & 1.66 & 2 & $\mathrm{NS}$ \\
Mean Hospitalization stay (hours) & 94 & 124 & $\mathrm{~S}$ \\
Infection rate & 0 & 1 & $\mathrm{~S}$ \\
Alignment & 0 & 0 & $\mathrm{NS}$ \\
\hline
\end{tabular}

$S=$ Significant $p$ value $\leq 0.05$, NS=Not significance $p$ value $>0.05$

When we compare the two group (including close and open cases) group 1 treatment with IMN, group 2 treatment with ORIF with BP, there is significant statistical difference between the two groups regarding the Union rate time, hospitalization stay and rate of infection, but no statistical difference regarding the mean operation time and functional outcome (using Harris Hip Score (HHS)) (Table 3). 
Table 3. The overall result of the patient's treatments

\begin{tabular}{cccc}
\hline Results of treatment & $\begin{array}{c}\text { Group 1/IMN } \\
\text { Number=10 }\end{array}$ & $\begin{array}{c}\text { Group 2/BP } \\
\text { Number=3 }\end{array}$ & P value \\
\hline Mean union time (weeks) & 16.2 & 22.17 & $\mathrm{~S}$ \\
Number of nonunion & 0 & 2 & $\mathrm{~S}$ \\
Mean operative Time(hours) & 1.59 & 1.43 & $\mathrm{NS}$ \\
Infection rate & 0 & 2 & $\mathrm{~S}$ \\
Mean time for hospital stay (hours) & 82 & 110 & $\mathrm{~S}$ \\
Alignment & 0 & 2 & $\mathrm{~S}$ \\
Functional outcome, Harris Hip Score & 82 & 79 & $\mathrm{NS}$ \\
\hline
\end{tabular}

$S=$ Significant $p$ value $\leq 0.05$, NS $=$ Not significance $p$ value $>0.05$

One of the complications that happen during follow up of the patients as one case of group 2 closed fracture develop femoral neck fracture after 13 weeks from the surgery while begin full weight bearing.

We had two cases in group 2 develop infection; one was a closed fracture had developed postoperative superficial wound infection treated with antibiotics and local care of the wound and the other had deep infection postoperatively that require removal of the implant after the fracture union.
One of the cases in closed fracture treated with open reduction and blade plate fixation develop varus mal-alignments.

No patient had shortening more than $2 \mathrm{~cm}$ in both group.

No statistical differences (p-value 0.813) regarding the functional outcome as we calculate the HHS at 6 months postoperatively and shown that the mean of HHS for IMNgroup 82 and the mean HHS for Blade plate group were 79 (Table 4).

Table 4. Functional outcome using Harris Hip Score at 24 weeks postoperatively

\begin{tabular}{cccc}
\hline Harris Hip Score & Results & $\begin{array}{c}\text { IMN group } \\
\mathbf{N = 1 8}\end{array}$ & $\begin{array}{c}\text { BP group } \\
\mathbf{N = 1 2}\end{array}$ \\
\hline $90-100$ & excellent & 3 & 2 \\
$80-89$ & good & 8 & 3 \\
$70-79$ & fair & 6 & 5 \\
$<69$ & poor & 1 & 2 \\
\hline
\end{tabular}

\section{Discussion}

There are no roles for conservative management for subtrochanteric fractures as shown by DeLee et al. ${ }^{(13)}$.

Current study shows the mean age of both groups between 40-60 years (graph-1). The incidence of fracture in the current study are more common in male than female, this can be attributed to socioenviromental factors that the females in our society are less involved in high activity level and hard work. The same result of the study done by Sridhar and
Neelakrishman that they shown the male were more prone to sustain proximal femoral fracture and he attribute it to the fact that male Indian were more active and more mobile than females who are confined to house hold activities ${ }^{(14)}$. The main cause of fractures in younger age group was a road traffic accident while in elderly patients, low energy trauma like fall on ground.

Kuzyk et al. (15) meta-analysis suggest for better outcome when compare between the fixation technique to separate the young age group 
with high-energy trauma from elderly patients with low energy trauma.

Mean union time in close intramedullary group was earlier (16.38 weeks) than close fractures Blade plate (22 weeks). Also, the mean union time of open fractures intramedullary group was more earlier (16.1 weeks) than open fractures of angled blade plate group (22.67 weeks), and the overall union time for intramedullary group earlier than blade plate groups and this relation was statistically significant $(P$ value $<0.05)$. The union rate was markedly delayed in cases that develop infections (32 weeks).

Pelet et al. radiological assessments for subtrochanteric fracture mean union time was 4.2 months for intramedullary group and 6.3 months for plate group (16).

We had two cases of nonunion both in Blade plate group, one was closed fracture and the other was open fractures and no reported cases of non-union in this study for intramedullary Nail. We think that the fracture treated by open way (Blade plate group) may impair the vascularity of the bone and affect the union process. Celebi et al. (17) reported better results when using fixed angle blade plate with minimum invasive technique.

Mean hospitalization stay for open fractures longer than close fractures probably related to the care for the open wound and postoperative injectable antibiotics in hospital, while the intramedullary nail group mean hospital stay (close fractures $70 \mathrm{hrs,} \mathrm{open} \mathrm{fractures} 94 \mathrm{hrs}$ ) shorter than Blade plate group (closed fractures $96 \mathrm{hrs}$, open fractures $110 \mathrm{hrs}$ ).

Because in our study, we exclude the concomitant head, chest or multiple organ injuries, the average time between the admission to the orthopedic surgical ward and the surgery were between $24-48$ hours, as the most of authors recommend early surgical fixation within 24 hours ${ }^{(18)}$. While if there were associated head and chest injuries, early surgical femoral fixation increases the morbidity and mortality as shown by series of study done by Pape et al. ${ }^{(19)}$, Jaick et al. ${ }^{(20)}$ and Townsend et al. (21).

Despite the use of prophylactic antibiotic and local care of wound, there were two infected cases (16\%) in Blade plate group. While no infection in IMN group (statistically significant) and correlate with study done by Miedel et al. (22) in 2005 as the infection rate was $8 \%$ and high revision rate $16 \%$ in extramedullary device in comparison with IMN.

In our study, one case (8\%) develop varus deformity in Blade plate group that happen when the patient begins weight bearing, these may be explained by biomechanical properties of the plate as it loads bearing device. Patel et al. (23) show in his study the rate of varus malalignment $5 \%$ and one of them infected that required a revision surgery.

No statistical difference between both techniques (Intramedullary and Extramedullary) regarding the functional outcome using HHS ( $p$ value $<0.05$ ), but it is greatly affected (poor HHS) in infected and nonunion cases, there was only minimal changes in Harris hip score after the interval of 6 months (24).

Roy and Subramanyam ${ }^{(25)}$ in 2014 was shown that the HHS mean was 80.7 for the subtrochanteric cases treated by Intramedullary Nail. Patel et al. ${ }^{(23)}$ in his study in India 2016 shown the mean of Harris hip score for intramedullary Nail was 81.3 and the extramedullary fixation was 85 .

Comparative study between intramedullary nail and fixed angle blade plate have been reported ${ }^{(26,27)}$.

The advantage of the IMN over the BP (28), is that it is stronger biomechanically, the device was load shearing (not load bearing) which allow fracture compression, less exposure of the fracture site, less blood loss and excellent rate of union. The distal locking screw were maintained the rotation and length control so earlier weight bearing achieved. However, the surgery had technical difficulties related to the entry site, reduction of the fractures, free hand technique for distal locking screws and long learning curve for surgeon experience.

The main disadvantage related to the ORIF with Blade plate were in large surgical exposure, sever damage to the soft tissue, more blood loss and nonunion. and due to the effect of load sharing on the plate that may result in fatigue breakage, but the plate fixation still 
preferable in fractures that extend to proximal trochanter, fractures of lateral wall and narrowing of the femoral medullary canal as the main advantage in these methods of fixation was the preservation of the blood supply to the medial fragments if the dissection and fixation were done by biological method (29).

The outcome of our study was in agreement with the general trend toward the use of IMN fixation method for Subtrochanteric fracture. In addition, the overall results of IMN were better than Blade plate fixation as showed by Parker et al. ${ }^{(30)}$.

Limitation of this study were in small sample size, not double blind so there are surgeon biases, no special type of classification used in our study so we are not compare specific type of subtrochanteric fractures and the surgical experience of the surgeon affect the outcome. Closed reduction and internal fixation with Intramedullary Nail (under the aid of fluoroscopic control) is preferable (for closed and open Gustilo's type-1 Subtrochanteric femoral fractures) when compared to the open reduction and Internal Fixation with 95-angled Blade Plate.

We recommend further studies like, studies with large sample size, studies including more severe types of open fractures (like Gustilo's type-2) and studies that comparing the Intramedullary nail to other modalities of Extramedullary devices like locked plate or Dynamic condylar screws.

\section{Acknowledgments}

The authors thank Al-Imamein Al-Kadhimein Medical city and Al-Wasity Teaching Hospital staff for providing all operative facilities.

\section{Authors contribution}

The patients were operated on and followed for their outcome by dr. Joda and Dr. Abd Ali. Research conduction and statistical analysis done by dr. Joda and Aldookhi.

\section{Conflict of interest}

Current study enrolled a small sample size, not double blinded, so there are surgeon biases, no special type of classification used in our study so authors are not compare specific type of subtrochanteric fractures and the surgical experience of the surgeon affect the outcome.

\section{Funding}

The authors offer all funding research.

\section{References}

1. Wiss DA, Brien WW. Subtrochanteric fractures of the femur results of treatment by interlocking nailing. Clin Orthop Relat Res. 1992; 283: 231-6.

2. Sims SH. Subtrochanteric femur fractures. Orthop Clin North Am. 2002; 33(1): 113-26, viii.

3. Bedi A, Toan Le T. Subtrochanteric femur fractures. Orthop Clin North Am. 2004; 35(4): 473-83.

4. Desai SJ, Wood KS, Marsh J, et al. Factors affecting transfusion requirement after hip fracture: can we reduce the need for blood? Can J Surg. 2014; 57(5): 342-8.

5. Alobaid A, Harvey EJ, Elder GM, et al. Minimally invasive dynamic hip screw: prospective randomized trial of two techniques of insertion of a standard fixation device J Orthop Trauma. 2004; 18(4): 207-12.

6. Kummer FJ, Olsson $O$, Pearlman $C A$ et al. Intramedullary versus Extramedullary fixation of subtrochanteric fractures. A biomechanical study. Acta Orthop Scand. 1998; 69(6): 580-4.

7. Rahme DM, Harris IA. Intramedullary nailing versus fixed angle blade plating for subtrochanteric femoral fractures: a prospective randomised controlled trial. J Orthop Surg (Hong Kong). 2007; 15(3): 278-81. doi: 10.1177/230949900701500306.

8. Craig NJ, Sivaji C, Maffulli N. Subtrochanteric fractures. A review of treatment options. Bull Hosp Jt Dis. 2001; 60(1): 35-46.

9. Nork SE, Reilly MC. Subtrochanteric fractures of the femur. In: Browner BD, Jupiter JJ, Levine AM, et al (eds). Skeletal trauma. 4th ed. Philadelphia: WB Saunders; 2009. p. 1832-78.

10. Waddell JP. Subtrochanteric fractures of the femur: a review of 130 patients. J Trauma. 1979; 19(8): 58292.

11. Kloen P, Rubel IF, Lyden JP, et al. Subtrochanteric fracture after cannulated screw fixation of femoral neck fractures: a report of four cases. J Orthop Trauma. 2003; 17(3): 225-9.

12. Goh SK, Yang KY, Koh JS, et al. Subtrochanteric insufficiency fractures in patients on alendronate therapy: a caution. J Bone Joint Surg Br. 2007; 89(3): 349-53. doi: 10.1302/0301-620X.89B3.18146

13. Delee JC, Clanton TO, Rockwood CA Jr. Closed treatment of subtrochanteric fractures of the femur in a modified cast-brace. J Bone Joint Surg Am. J Bone Joint Surg Am. 1981; 63(5): 773-9. doi: http://dx.doi.org/10.2106/00004623-19816305000012.

14. Sridhar M, Neelakrishman R. Study of various modalities of surgical management of unstable 
intertrochanteric fractures. Int J Modern Res Rev. 2009; 2: 421-7.

15. Kuzyk PR, Bhandari M, Mckee MD, et al. Intramedullary versus extramedullary fixation for subtrochanteric femur fractures. J Orthop Trauma. 2009; 23(6): 465-70. doi: 10.1097/BOT.0b013e3181acfdfd.

16. Pelet S, Arlettaz Y, Chevalley F. [Osteosynthesis of per- and subtrochanteric fractures by blade plate versus gamma nail. A randomized prospective study]. Swiss Surg. 2001; 7(3): 126-33. doi: http://dx.doi.org/10.1024/1023-9332.7.3.126.

17. Celebi L, Can M, Muratli HH, et al. Indirect reduction and biological internal fixation of comminuted subtrochanteric fractures of the femur. Injury. 2006; 37(8): 740-50. doi: 10.1016/j.injury.2005.12.022.

18. Brundage $\mathrm{SI}, \mathrm{McGhan} \mathrm{R}$, Jurkovich $\mathrm{GJ}$, et al. Timing of femur fracture fixation: effect on outcome in patients with thoracic and head injuries. J Trauma. 2002; 52: 299-307.

19. Pape HC, Auf'm'Kolk M, Paffrath T, et al. Primary intramedullary femur fixation in multiple trauma patients with associated lung contusion-a cause of posttraumatic ARDS? J Trauma. 1993; 34(4): 540-7; discussion 547-8.

20. Jaicks RR, Cohn SM, Moller BA. Early fracture fixation may be deleterious after head injury. J Trauma. 1997; 42(1):1-5; discussion 5-6.

21. Townsend RN, Lheureau T, Protech J, et al. Timing fracture repair in patients with severe brain injury (Glasgow Coma Scale score <9). J Trauma. 1998; 44(6): 977-82; discussion 982-3.

22. Miedel $R$, Ponzer $S$, Törnkvist $H$, et al. The standard Gamma nail or the Medoff sliding plate for unstable trochanteric and subtrochanteric fractures. A randomised, controlled trial. J Bone Joint Surg $\mathrm{Br}$. 2005, 87(1): 68-75.
23. Patel R, Menon $H$, Chaudhari $N$, Chaudhari V. Subtrochanteric femur fractures treated with extramedullary or intramedullary fixation at tertiary care centre. Int J Med Sci Public Health. 2017; 6(2), doi: 10.5455/ijmsph.2017.13062016582.

24. Söderman P, Malchau H. Is the Harris hip score system useful to study the outcome of total hip replacement? Clin Orthop Relat Res. 2001; (384): 189-97.

25. Roy GK, Subramanyam Y. Study of management of subtrochanteric fracture femur by proximal femoral nailing. Int J Pharma Bio Sci 2014; 5(1): (B) 1112-6.

26. Hardy DC, Descamps PY, Krallis $P$, et al. Use of an intramedullary hip-screw compared with a compression hip-screw with a plate for intertrochanteric femoral fractures. A prospective, randomized study of one hundred patients. J Bone Joint Surg Am. 1998; 80(5): 618-30.

27. Bridle $S H$, Patel $A D$, Bircher $M$, et al. Fixation of subtrochanteric fractures of the femur. A randomised prospective comparison of the gamma nail and the dynamic hip screw. J Bone Joint Surg Br. 1991; 73(2): 330-4.

28. Taneja DK. Subtrochanteric fracture-Recent advances in management. In Taneja DK (ed). Recent trend in fracture management. 2001. p. 39-43.

29. Micic ID, Mitkovic MB, Park IH, et al. Treatment of subtrochanteric femoral fractures using selfdynamisable internal fixator. Clin Orthop Surg. 2010; 2(4): 227-31. doi: 10.4055/cios.2010.2.4.227.

30. Parker MJ, Dutta BK, Sivaji C, et al. Subtrochanteric fracture of the femur. Injury. 1997; 28(2): 91-5.

\section{Correspondence to dr. Ahmed I. Joda \\ E-mail: AhmedJoda79@yahoo.com Received May 29 2017 Accepted Nov. $2^{\text {nd }} 2017$}

